\title{
Pelembagaan Regional mengenai Hak Asasi Manusia di ASEAN
}

\section{Ludiro Madu}

Program Studi Hubungan Internasional UPN "Veteran" Yogyakarta, Condongcatur, Yogyakarta 55283

Email: ludiro@gmail.com

Submitted: 21 November 2015, Accepted: 18 February 2016

\begin{abstract}
Institutionalization of non-traditional issues has become new phenomenon for ASEAN, including those related to human rights in the form of ASEAN Intergovernmental Commission on Human Rights (AICHR). While its instutionalization has been one of ASEAN's achievements for its sensitive characters, the AICHR also revealed several complexities. The first problem is related to ASEAN's further attempts for boosting regional cooperation on human rights among its member states. Diversified political system of ASEAN's states is deemed as its obstacle. The second refers to regional architecture of ASEAN which is prone to be loosely structured and more focussed on economic development and regional political stability. This paper seeks to explain dynamics among ASEAN's member states in institutionalizing human rights issues. AlCHR has been one of the most successful ASEAN's achievements in managing non-traditional issues and promoting participation of non-state actors in this region. In doing so, this paper also shows tug-of-war between regional and national interests in the process of formulating regional regime on human rights in ASEAN.

Keywords: AICHR, human rights, regional institutionalization, national interest, non-interference, ASEAN
\end{abstract}

\begin{abstract}
Abstrak
Pelembagaan isu-isu keamanan non-tradisional telah menjadi semacam fenomena baru bagi ASEAN, khususnya berkaitan dengan hak asasi manusia (HAM) melalui ASEAN Intergovernmental Commision on Human Rights (AICHR). Padahal persoalan HAM selalu menjadi isu sensitif di antara negaranegara di kawasan Asia Tenggara. Meskipun demikian, pelembagaan rezim HAM dalam kerangka ASEAN tetap memiliki beberapa kesulitan. Persoalan pertama berkaitan dengan upaya-upaya mendorong kerjasama hak asasi manusia di antara negara-negara anggota ASEAN. Kesulitan tersebut lebih disebabkan oleh keragaman sistem politik negara-negara anggota. Alasan kedua adalah arsitektur regional ASEAN sendiri yang cenderung memiliki struktur agak longgar dan lebih fokus pada pembangunan ekonomi dan stabilitas politik regional. Melalui AICHR, tulisan ini hendak menjelaskan dinamika di antara negara-negara anggota ASEAN dalam melembagakan isu-isu HAM secara regional. AICHR merupakan capaian regional dalam mengelola persoalan-persoalan non-keamanan tradisional dan mendorong partisipasi aktor-aktor non-negara di ASEAN. Oleh karena itu, bahasan mengenai AICHR akan menunjukkan tarik-menarik antara kepentingan regional dan nasional dalam perumusan rezim regional mengenai hak azasi manusia ini.

Keywords: AICHR, hak azasi manusia, kedaulatan, non-intervensi, ASEAN
\end{abstract}

\section{PENDAHULUAN}

Dalam perkembangan ASEAN sebagai institusi regional, pembentukan ASEAN Intergovernmental Commision on Human Rights (AICHR) pada 23 Oktober 2009 pada 15th ASEAN Summit telah meningkatkan optimisme regional terhadap ASEAN. Pertama, pelembagaan HAM ke dalam AICHR menandai permulaan organisasi regional ini memberikan perhatian kepada isu-isu keamanan nontradisional, seperti pemberantasan terorisme (ASEAN
Convention on Countering Terrorism/ACCT, asap dan polusi lintas-batas negara (ASEAN Convention on Transboundary Haze and Pollution/ACTHP), dan penanganan bencana alam (ASEAN Humanitarian Action Center/AHA Center).

Optimisme kedua adalah bahwa pembentukan AICHR juga mencerminkan peningkatan participatory regionalism (Madu, 2013). Dalam usia 48 tahun ini, ASEAN telah memberi akses semakin besar terhadap 
partisipasi kelompok-kelompok masyarakat (khususnya lembaga swadaya masyarakat/LSM) dalam mendiskusikan berbagai persoalan di tingkat regional. ASEAN mulai membuka diri terhadap peran dan kontribusi konstruktif dari berbagai lapisan masyarakat di kawasan ini dalam mengelola persoalan-persoalan potensial yang kurang atau tidak menjadi perhatian pemerintah-pemerintah negara anggota ASEAN.

Berkaitan dengan faktor kedua, optimism ketiga adalah bahwa AICHR merupakan pengakuan ASEAN terhadap capacity agency dari masyarakat. Perbedaan sistem politik dan pemerintahan di negara-negara anggota ASEAN berimplikasi pada perbedaan pola hubungan antara pemerintah dengan masyarakatnya. Namun demikian, perbedaan tersebut tidak menghalangi komitmen dan kemampuan kelompokkelompok LSM regional dalam mendorong berbagai perundingan menuju pembentukan AICHR pada 2009. Kelompok masyarakat dari negara-negara tertentu tetap dapat berkontribusi positif dalam berbagai perundingan mengenai HAM, tanpa memperoleh hambatan berarti dari pemerintahnya.

Seiring dengan perkembangan kepentingan dan desakan masyarakat internasional, isu penegakan HAM menjadi isu penting dan integral di ASEAN.

Pergeseran kepentingan ASEAN ini disebabkan oleh pengakuan komunitas internasional terhadap ASEAN sebagai aktor regional yang semakin signifikan.

Pergeseran orientasi paradigma ASEAN dari pendekatan yang berpusat pada negara ke arah pendekatan yang berorientasi pada komunitas menjadi karakter baru dari ASEAN seiring dengan bergabungnya Brunei Darussalam (1984), Vietnam (1995), Laos dan Myanmar (1997), dan Kamboja (1999).

Namun demikian, proses pembentukan AICHR atau Badan HAM ASEAN ternyata bukannya tanpa persoalan. Sepanjang kiprahnya dalam penegakan HAM, setiap negara-negara anggota ASEAN memiliki sikap berbeda dalam menangani segala persoalan terkait penegakan HAM di masing-masing negara. Hal ini terkait dengan sistem pemerintahan yang berbedabeda yang secara tidak langsung mempengaruhi interpretasi masing-masing negara mengenai masalah HAM. Kebebasan berekspresi dan berpendapat disikapi berbeda-beda oleh masing-masing negara anggota ASEAN. Selain itu, prinsip non-intervensi dan konsensus dalam proses pengambilan keputusan dipandang membatasi ruang gerak penegakan HAM di kawasan Asia Tenggara.

Melalui AICHR, tulisan ini hendak menjelaskan dinamika di antara negara-negara anggota ASEAN dalam melembagakan isu-isu HAM secara regional. AICHR merupakan capaian regional dalam mengelola persoalan-persoalan non-keamanan tradisional dan mendorong partisipasi aktor-aktor non-negara di ASEAN. Rezim regional HAM dalam bentuk AICHR tidak hanya mampu melengkapi sistem HAM PBB tetapi juga mampu beroperasi dalam konteks regional. Pada gilirannya AICHR diharapkan dapat mempromosikan upaya-upaya regional dalam penegakan HAM di antara ke-10 negara anggota ASEAN, khususnya dalam menekankan arti penting keamanan masyarakat atau manusia menuju Komunitas ASEAN pada akhir 2015 mendatang.

\section{PEMBAHASAN}

\section{KONDISI HAK ASASI MANUSIA (HAM) DI ASEAN}

Hak asasi manusia selalu menjadi isu sensitif di antara negara bagian di Asia Tenggara. Upaya-upaya mengembangkan rezim hak asasi manusia dalam kerangka ASEAN telah menjadi agenda penting sebagai akibat dari kesulitan dalam mendorong kerjasama di tingkat ASEAN (Hashimoto, 2004). Alasan pertama adalah keragaman negara anggota dan ambivalensi mereka terhadap hak asasi manusia. Kawasan Asia Tenggara memiliki perbedaan dalam pelaksanaan Declaration of Human Rights dengan negara-negara barat yang umumnya hanya mementingkan freedom dan democracy dan individualisme sebagai aspek pokok dari Declaration of Human Rights (Katsumata, 2009). Alasan kedua berkaitan erat dengan karakter ASEAN sebagai organisasi regional. ASEAN telah menjadi organisasi yang agak longgar terstruktur terutama difokuskan pada pembangunan ekonomi dan keamanan politik. Selain itu, norma-norma inti dari konsensus berbasis 
pengambilan keputusan dan non-interference dalam isu-isu domestic atau ASEAN Way telah membuat prospek untuk kerjasama yang lebih tegas sangat diragukan (Phan, 2009).

Sebelum AICHR dibentuk pada 2009, Asia khususnya Asia Tenggara - merupakan satu-satunya kawasan yang tidak memiliki mekanisme HAM. Pernyataan ASEAN Civil Society Groups Unite for Human Rights Body Advocacy pada 7 Agustus 2008 menegaskan "Asia, including ASEAN, remains the only region in the world that does not have a regional human rights mechanism" (ASEAN civil society groups unite for human rights body advocacy) (HRWGIndonesia). Namun demikian, upaya pembentukan mekanisme HAM ASEAN ternyata sudah dipertimbangkan sejak Joint Communique of the 26th ASEAN Ministerial Meeting (AMM) di Singapura, Juli 1993.

Indeks pengukuran dari World Justice Project pada tahun 2010 (WJP, 2015) melihat kepatuhan terhadap aturan hukum dalam praktek di berbagai negara. Meskipun indeks ini sangat terbatas, tetapi indeks ini masih dapat memberikan beberapa derajat indikasi kondisi hak asasi manusia. Kepatuhan terhadap aturan hukum merupakan landasan penting dalam upaya mencapai pemerintah yang akuntabel dan perlindungan hak asasi manusia. Namun demikian laporan 2010 hanya memeringkatkan 4 (empat) negaranegara ASEAN (WJP, 2015).

Menurut laporan 2010 itu, Indonesia, Thailand, dan Filipina tingkat signifikan lebih rendah dari negara-negara kaya di kawasan ini dan dunia barat, namun mereka melakukan relatif baik dibandingkan dengan negara-negara dari wilayah lain di dunia dengan tingkat pendapatan yang sama. Sebagai kontras, Singapura adalah peringkat teratas di antara negaranegara di indeks dalam memberikan keamanan dan akses terhadap keadilan sipil untuk warga negaranya. Namun Singapore menempati urutan sangat rendah dalam hal pemerintahan yang terbuka, kekuasaan pemerintah terbatas, dan hak-hak dasar. Ini memberitahu kita bahwa setidaknya dalam empat negara, aturan hukum relatif kuat dalam menciptakan dasar potensi untuk perlindungan hak asasi manusia
(WJP, 2015).

Sumber lain indikasi untuk situasi HAM di negaranegara anggota ASEAN adalah tentu saja laporan negara dari berbagai organisasi hak asasi manusia. Kondisi hak asasi manusia di negara-negara ASEAN umumnya telah banyak dinilai oleh kelompok pemantau internasional hak asasi manusia sebagai kondisi hak asasi manusia yang miskin (CaballeroAnthony, 1995). Dokumentasi dari LSM di seluruh dunia seperti Amnesty International, Human Rights Watch, organisasi hak asasi manusia regional dan nasional masih mengungkapkan berbagai pelanggaran hak asasi manusia di kawasan ASEAN.

Kebutuhan untuk komitmen yang kuat akan hak asasi manusia dan rezim regional hak asasi manusia telah lama terlihat di antara negara-negara anggota ASEAN, baik dari segi perkembangan positif di kawasan ini maupun juga dari aspek kekurangannya. Di sisi positif, kenyataan mengatakan bahwa dalam konteks nasional, yakin ASEAN telah membuat hak asasi manusia merupakan bagian dari agenda nasional mereka. Beberapa konstitusi memuat ketentuan tentang hak asasi manusia dan beberapa negara juga telah mengembangkan rencana aksi nasional hak asasi manusia (Thio, 2008). Selain itu, empat dari negara anggota ASEAN juga telah memiliki lembaga hak asasi manusia yang mengatur pada tingkat nasional. Di Indonesia terdapat Komisi Nasional Hak Asasi Manusia atau yang lebih dikenal dengan Komnas HAM, di Malaysia terdapat Suruhanjaya Hak Asasi Manusia Malaysia (Suhakam), di Filipina terdapat Campaign for Human Rights in the Philippines (CHRP) dan ada di Thailand yaitu Khammakarn Sithi Manusayachon Hang Chart (Khamakarn Sit). Lembagalembaga tersebut menyediakan proses check and balance terhadap penyalahgunaan kekuasaan.

Negara-negara anggota ASEAN cenderung lambat atau enggan untuk membangun kerjasama yang lebih tegas hak asasi manusia di tingkat regional dibandingkan dengan negara-negara di kawasan lain. Hal ini didasarkan pada sejumlah faktor yang dapat menjelaskan lambatnya kemajuan terhadap hak asasi manusia di wilayah ASEAN ini. Carlos Medina telah 
menangkap beberapa alasan utama biasanya diajukan untuk menjelaskan kurangnya suatu rezim hak Asia Tenggara manusia:

"HAM masalah dianggap oleh banyak negara sebagai urusan internal, sedangkan negara menerima konsep universalitas hak asasi manusia, ia berpendapat bahwa perbedaan substansial ada antara norma internasional hak asasi manusia dan kebiasaan dan praktik di kawasan ini; banyak negara percaya hak-hak individu harus memberi jalan kepada tuntutan keamanan nasional dan pertumbuhan ekonomi, atau bahwa hak asasi manusia dapat direalisasikan setelah tingkat tertentu kemajuan ekonomi telah dicapai, dan mekanisme hak asasi manusia tidak mungkin mencakup seluruh rentang perbedaan di antara negara-negara di kawasan ini di hal latar belakang sejarah, budaya dan tradisi, agama dan tingkat perkembangan ekonomi dan politik (Askew, 2004)."

Hak asasi manusia dengan segala sifatnya memerlukan perjanjian yang mengikat secara hukum dan kemauan politik untuk menegakkan perjanjianperjanjian dan sanksi oleh negara terhadap negara ketika gagal untuk melakukannya. Sementara rezim hak asasi manusia regional dalam ASEAN telah dianggap mungkin untuk dibentuk, pada saat yang sama tidak mengherankan bahwa kesimpulan yang dicapai oleh penelitian sebelumnya berpendapat bahwa rezim itu hanya akan fokus pada promosi hak asasi manusia dan bukan perlindungan dan mekanisme penegakan hukum. Dengan cara itu, pemerintah dapat berpartisipasi tanpa takut mengorbankan hak-hak kedaulatan mereka (Hashimoto, 2004).

\section{PROMOSI DEMOKRASI DAN HAM DI ASIA TENGGARA}

Tingkat demokrasi dan pembangunan ekonomi biasanya dianggap sebagai faktor yang paling signifikan dalam mempengaruhi pendekatan hak asasi manusia di negara-negara ASEAN dan menjelaskan lambatnya pembangunan (Peerenboom, 2006). Sistem politik dan situasi demokrasi di negara-negara ASEAN menunjukkan keberagaman yang besar. Dalam hal demokrasi, mereka telah dikategorikan sebagai negara- negara demokratis sampai negara semi-demokratis dan negara semi otoriter sampai negara otoriter (Eldridge, 2002). Negara-negara seperti Filipina, Indonesia dan Thailand merupakan sejarah politik dari negara otoriter menjadi negara demokratis. Kamboja, Malaysia dan Singapura memiliki keunikan mereka sendiri demokrasi Asia yang tidak liberal. Pembangkangan dan advokasi sistem alternatif pada kenyataannya terpinggirkan di Malaysia dan secara praktis dilarang di Singapura. Negara komunis pihak tunggal ada di Vietnam dan Laos. Myanmar diperintah oleh junta militer otoriter sementara Brunei berada di bawah aturan jinak tetapi tetap dibawah keotoriteran Sultan (Eldridge, 2002).

Tabel 1.

Tingkat Kebebasan di Negara-negara ASEAN

\begin{tabular}{|c|c|}
\hline Penilaian Rata-rata & Nilai \\
\hline \multicolumn{2}{|l|}{ Bebas } \\
\hline Indonesia & 2,5 \\
\hline \multicolumn{2}{|l|}{ Bebas Sebagian } \\
\hline Filipina & 3,5 \\
\hline Malaysia & 4,5 \\
\hline Singapore & 4,5 \\
\hline \multicolumn{2}{|l|}{ Tidak Bebas } \\
\hline Brunei Darussalam & 5,5 \\
\hline Kamboja & 5,5 \\
\hline Laos & 6 \\
\hline Vietnam & 6 \\
\hline Myanmar & 7 \\
\hline
\end{tabular}

Sumber:http://www.freedomhouse.org/template.cfm?page=25\&year=2010, diakses pada 11 Agustus 2015.

Tabel 1 menunjukkan survei peringkat kebebasan di dunia, sebuah alat yang dapat digunakan untuk menilai situasi demokrasi di negara-negara. Indeks tahun 2010 menunjukkan bahwa Indonesia sebagai negara "bebas", Malaysia, Filipina, Singapura, dan Thailand sebagai negara "bebas sebagian", dan sisanya adalah negara "tidak bebas". ${ }^{1}$ Ekonomi dan tingkat pembangunan menampilkan perbedaan yang terlihat. Singapura dapat dikatakan sebagai negara dengan 
tingkat ekonomi dan pembangunan paling tinggi di ASEAN, sedangkan Myanmar dan Kamboja merupakan yang paling rendah dan negara-negara ASEAN lainnya berada di berbagai tingkatan lainnya.

Tabel 2. Human Development Index

\begin{tabular}{lll}
\hline $\begin{array}{l}\text { Human Development } \\
\text { IndexRanking 2010 }\end{array}$ & $\begin{array}{l}\text { HDI } \\
\text { Ranking }\end{array}$ & $\begin{array}{l}\text { GDP per } \\
\text { Capita USD }\end{array}$ \\
\hline $\begin{array}{l}\text { Very High Human } \\
\text { Development }\end{array}$ & & \\
$\begin{array}{l}\text { Singapore } \\
\text { Brunei Darussalam }\end{array}$ & 27 & 50266 \\
$\begin{array}{l}\text { High Human } \\
\text { Development }\end{array}$ & & 49915 \\
$\begin{array}{l}\text { Malaysia } \\
\text { Medium Human }\end{array}$ & 57 & 14410 \\
$\begin{array}{l}\text { Development } \\
\text { Thailand }\end{array}$ & 92 & 8328 \\
$\begin{array}{l}\text { Philippines } \\
\text { Indonesia }\end{array}$ & 97 & 3061 \\
$\begin{array}{l}\text { Vietnam } \\
\text { Lao PDR }\end{array}$ & 108 & 4394 \\
Cambodia & 122 & 3097 \\
Low Human & 124 & 19504 \\
$\begin{array}{l}\text { Development } \\
\text { Myanmar }\end{array}$ & 132 & 1596 \\
\hline
\end{tabular}

Sumber: http://hdr.undp.org/en/humandev/, diakses pada 7 Agustus 2015

Tabel 2 menyajikan angka-angka dari Indeks Pembangunan Manusia (IPM) dikombinasikan dengan Produk Domestik Bruto per kapita di masing-masing negara. HDI ini dirancang oleh United Nations Development Programe (UNDP) dan mengukur pembangunan dengan menggabungkan indikator harapan hidup, pencapaian pendidikan dan pendapatan (UNDP, 2015). Demokrasi dan hak asasi manusia adalah konsep yang berbeda tetapi terkait. Keduanya memiliki definisi tunggal dan keduanya sangat kompleks dan tergantung pada interpretasi yang berbeda dalam masyarakat yang berbeda. David Beetham menegaskan bahwa "demokrasi dan hak asasi manusia menempati berbagai wilayah di dunia politik. Satu adalah masalah organisasi pemerintahan sementara yang lain soal hakhak individu dan pertahanan mereka" (Petcharamesree, 2009).

Demokrasi dan hak asasi manusia adalah konsep yang berbeda tetapi terkait. Keduanya sangat kompleks dan tergantung pada interpretasi yang berbeda dalam masyarakat yang berbeda. David Beetham menegaskan bahwa "demokrasi dan hak asasi manusia menempati wilayah berbeda di dunia politik, yang satu menempati wilayah organisasi pemerintahan sementara yang lain dari mempertanyakan hak-hak individu dan pertahanan mereka." Konstitusi negara-negara anggota ASEAN, misalnya, menunjukkan bahwa hak dan kebebasan rakyat diakui secara cukup baik, setidaknya di beberapa negara ASEAN. Namun demikian, demokrasi sering dipahami secara berbeda antara negara-negara Barat dan negara-negara di Asia Tenggara. Untuk beberapa negara, definisi Barat tentang demokrasi, HAM, dan pluralisme politik telah dan masih dianggap sebagai ancaman terhadap keamanan dan stabilitas dalam negara. Dalam sebagian besar negara ASEAN, kebebasan pers, politik dan hak-hak sipil individu, kebebasan berekspresi dan berkumpul pada khususnya telah dibatasi (Petcharamesree, 2009).

Demokrasi dan hak asasi manusia juga terkait dengan pengembangan dan pertumbuhan ekonomi dalam negara-negara anggota ASEAN. Jones bahkan berpendapat bahwa "tantangan terbesar yang dihadapi integrasi regional terletak dalam mengatasi kesenjangan pembangunan, bukan defisit demokrasi, di antara negara anggota" (Jones, 2008). Upaya untuk pembangunan ekonomi selalu dianggap tujuan utama di antara negara-negara anggota ASEAN. Kebanyakan dari mereka telah dinilai memiliki pembangunan ekonomi lebih tinggi dari hak asasi manusia dan berpendapat bahwa pertumbuhan ekonomi harus datang sebelum reformasi demokratis (Peerenboom, 2006). Mantan Menteri Luar Negeri Singapura, Wong Kan Seng, menegaskan bahwa kemiskinan telah dijadikan ejekan dari semua kebebasan sipil (CaballeroAnthony, 1995). Beberapa pemerintah telah menggunakan pentingnya pertumbuhan ekonomi sebagai argumen untuk membela kebutuhan untuk 
memerintah dengan tangan yang kuat (CaballeroAnthony, Human Rights, Economic Change and Political Development, 1995). Negara-negara seperti Singapura, Malaysia, dan Indonesia memberikan contoh bahwa pertumbuhan yang cepat dapat terjadi dalam kepemimpinan otoriter. Terutama Singapura, Singapura telah menantang gagasan bahwa demokrasi adalah kunci untuk pertumbuhan ekonomi, atau dengan kata lain bahwa pertumbuhan ekonomi akan mengarah ke politik reformasi, demokratisasi dan perlindungan peningkatan perlindungan hak asasi manusia (Peerenboom, 2006). Sebagai kontras, berdiri Filipina yang menghadapi reformasi demokrasi terlebih dahulu jauh sebelum banyak negara ASEAN lainnya tapi masih sedikit buruk dalam hal pertumbuhan ekonomi dan keamanan nasional. Terakhir, negaranegara seperti Myanmar dan Laos menampilkan kurang baiknya pertumbuhan ekonomi, demokratisasi, dan perbaikan dalam perlindungan hak asasi manusia.

Hubungan antara demokrasi, pembangunan, dan hak asasi manusia cenderung sangat kompleks dan tidak memiliki rumus yang tepat untuk kapan dan dalam kombinasi dengan apa perbaikan dalam salah satu dari tiga hal tersebut akan berlangsung. Mereka semua saling terkait dalam arti bahwa pertumbuhan dalam salah satu diantaranya dapat meningkatkan pertumbuhan yang lainnya, tetapi secara pasti tidak ada hubungan linier. Sementara demokrasi dapat dianggap sebagai prasyarat penting untuk mewujudkan hak asasi manusia, Peerenboom berpendapat bahwa kemajuan hak asasi manusia hanya terjadi sekali demokrasi telah mencapai tahap tertentu (Peerenboom, 2006). Keberagaman dalam sistem politik pemerintah dan tingkat perkembangan serta ditambah dengan kurangnya konsolidasi demokrasi, sangat mencerminkan pandangan negara-negara anggota ASEAN tentang demokrasi dan sikapnya terhadap pembangunan ekonomi. Sikap mereka inilah yang dalam banyak hal menjelaskan kebijakan dan praktek di bidang HAM di negara-negara anggota ASEAN (Petcharamesree, 2009). Ini mungkin adalah faktor yang paling penting mengapa nasional catatan HAM masih banyak kekurangan dan alasan untuk kurangnya kerjasama HAM regional dalam ASEAN. Selain itu, walaupun konsep-konsep seperti demokrasi, penghormatan terhadap hak asasi manusia, dan kebebasan dasar sekarang sudah dimasukkan dalam Piagam ASEAN, hal ini tidak menjadi jaminan untuk adanya implementasi yang sesuai.

\section{MELAWAN PRINSIP NON-INTERFERENCE?}

Hak Asasi Manusia (HAM) adalah sebuah elemen yang menonjol dalam isu non-interference di ASEAN. Para komentator dan organisasi-oraganisasi di dalam dan di luar Asia Tenggara telah memperdebatkan intervensi ASEAN dalam kasus pelanggaran HAM di negara anggotanya padahal ASEAN mempunyai prinsip dasar yaitu prinsip non-interference. Prinsip noninterference ASEAN pada kenyataannya telah menjadi batu sandungan tersendiri bagi ASEAN dalam hal penegakan HAM. Seharusnya makna non-interference dalam hal penegakan HAM harus jelas karena kita tidak bisa mengatakan bahwa persoalan pelanggaran HAM adalah persoalan domestik saja. Hal inilah yang kemudian memunculkan pertanyaan yang mendasar yaitu bagaimanakah ASEAN Intergovernmental Commission on Human Rights (AICHR) dapat terbentuk ditengah keberagaman nilai yang dimiliki oleh negaranegara anggota ASEAN dan masih dipegang teguhnya prinsip non-intervensi.

Bergabungnya negara-negara anggota ASEAN dan interaksi mereka pada rezim internasional secara langsung maupun tidak langsung mempengaruhi cara pandang dan perilaku mereka tentang HAM. United Nations atau Perserikatan Bangsa-Bangsa dengan segala mandatnya, terutama dengan Universal Declaration of Human Rigts nya, akan sedikit banyak mengatur tindakan negara-negara anggotanya tentang penghormatan akan nilai-nilai HAM (Wahyuningrum, 2009). Pada kenyataannya, pembentukan Komisi HAM ASEAN tidak terlepas dari campur tangan PBB. Mengingat seluruh negara anggota ASEAN ialah negara anggota PBB maka negara-negara tersebut mendukung segala upaya penegakan HAM baik di dalam maupun di luar negaranya (Wibowo, 2010). 
Tabel 3. Daftar Nama Negara Anggota ASEAN yang Menjadi Anggota PBB

\begin{tabular}{ll}
\hline Nama Negara & Tanggal Bergabung \\
\hline Brunei Darussalam & 21 September 1984 \\
Filipina & 24 Oktober 1945 \\
Indonesia & 28 September 1950 \\
Kamboja & 14 Desember 1955 \\
Laos & 14 Desember 1955 \\
Malaysia & 17 September 1957 \\
Myanmar & 19 April 1948 \\
Singapura & 21 September 1965 \\
Thailand & 16 Desember 1946 \\
Vietnam & 20 September 1977 \\
\hline
\end{tabular}

Sumber: "Member States of United Nations", http://www.un.org/en/ members/index.shtml diakses pada 9 Agustus 2015

Pada tingkat internasional, negara-negara anggota ASEAN selama bertahun-tahun telah semakin terlibat dalam perjanjian internasional utama PBB dalam hal hak asasi manusia. Partisipasi dalam instrumen hak asasi manusia dapat dilihat sebagai suatu kondisi yang cukup penting tetapi tidak dapat menilai komitmen negara dalam hal hak asasi manusia universal. Walaupun terkadang ratifikasi oleh negara-negara tidak sesuai dengan kinerja ataupun aplikasi mereka tetapi hal itu setidaknya sudah suatu bentuk penerimaan akuntabilitas internasional.

Pada tabel 4 dapat diketahui bahwa hanya 4 (negara) ASEAN yang mempunyai institusi HAM nasional, yaitu Malaysia dengan Human Rights Commision of Malaysia atau SUHAKAM, Thailand dengan National Human Rights Commision (Thailand), Filipina dengan Philippines Commission for Human Rights (PCHR), dan Indonesia dengan National Human Rights Commision atau yang biasa disebut dengan KOMNAS HAM. Semua negara ASEAN telah meratifikasi Convention of the Rights of the Child (CRC) dan Convention on Elimination of all Forms of Discrimination against Women (CEDAW). Dalam beberapa tahun terakhir, lebih banyak negara ASEAN telah menandatangani atau melakukan aksesi pada International Covenant on Civil and Political Rights (ICCPR) dan International Covenant on Economic Social and Cultural Rights
(ICESCR). Hal ini diyakini akan memberikan beban tambahan untuk kebutuhan rezim hak asasi manusia di ASEAN. Beberapa negara juga mengalami Review Periodik Universal PBB dan mengijinkan pelapor khusus tematik dari komite hak asasi manusia PBB untuk melakukan investigasi di tempat (UNHR, 2007).

Dalil-dalil utama yang dilahirkan UNHR ini pada akhirnya menjadi titik tolak ASEAN untuk ikut dalam Pakta Sun Servanda dan meratifikasi beberapa perjanjian yang berkaitan dengan dukungan terhadap penegakan HAM khususnya di kawasan Asia Tenggara. Dalam konteks pelaksanaannya, ternyata standar pengakuan HAM di setiap negara di ASEAN masih belum merata. Hal ini mengakibatkan beberapa konvensi tidak diratifikasi oleh beberapa negara dengan berbagai alasan. Hipotesis yang dapat ditarik adalah bahwa penegakan HAM di dalam negeri beberapa negara anggota belum siap untuk menerima intervensi dan keadilan merata di mata dunia.

Sejalan dengan ketentuan bahwa dalam mendukung Vienna Declaration and Programme of Action (VDPA), ASEAN juga harus mempertimbangkan pembentukan mekanisme hak asasi manusia regional yang sesuai. Kata "mekanisme hak asasi manusia regional yang sesuai" memang telah menimbulkan perdebatan dengan "Asian Values", konsolidasi kawasan dan membangun hubungan yang dapat dipercaya di tingat kawasan. Deklakrasi Hak Asasi Manusia pada tahun 1993 menyatakan bahwa tugas dan tanggung jawab negara-negara anggota adalah untuk membentuk mekanisme hak asasi manusia regional yang tepat (UNHR, 2007).

Pada KTT ASEAN ke-10 November 2004 di Vientiane, para pemimpin ASEAN resmi menegaskan maksud penyusunan Piagam ASEAN sebagaimana diatur pada tahun 2004. Pada KTT ASEAN 11 Desember 2005, pemimpin ASEAN mengeluarkan Deklarasi Kuala Lumpur pada Pembentukan Piagam ASEAN. Dalam deklarasi tersebut mereka berkomitmen pada piagam itu untuk menjadikan ASEAN sebagai sebuah asosiasi yang berlandaskan hukum dan kerangka kelembagaan untuk menunjang 
Tabel 4. Ratifikasi negara anggota ASEAN terhadap Instrumen HAM, 2010

\begin{tabular}{|c|c|c|c|c|c|c|c|c|c|c|c|c|c|}
\hline \multicolumn{14}{|c|}{ Ratification of International Human Rights Instruments as of November 2010} \\
\hline & NHRIs & ICERD & ICCPR & $\begin{array}{l}\text { ICCPR } \\
\text { OP I }\end{array}$ & $\begin{array}{l}\text { ICCPR } \\
\text { OP II }\end{array}$ & $\begin{array}{l}\text { IC } \\
\text { ES } \\
C R\end{array}$ & CRC & $\begin{array}{l}\text { CRC } \\
\text { OP I }\end{array}$ & $\begin{array}{l}\text { CRC } \\
\text { OP } \\
\|\end{array}$ & $\begin{array}{l}C E \\
D A \\
W\end{array}$ & $\begin{array}{l}\text { CED } \\
\text { AW } \\
\text { OP I }\end{array}$ & $\begin{array}{l}C \\
A \\
T\end{array}$ & $\begin{array}{l}C \\
A T \\
O \\
P\end{array}$ \\
\hline Singapore & & & & & & & $x$ & $x$ & & $x$ & & & \\
\hline Brunei & & & & & & & $x$ & & $x$ & $x$ & & & \\
\hline Malaysia & 2000 & & & & & & $x$ & & & $x$ & & & \\
\hline Thailand & 2001 & $x$ & $x$ & & & $x$ & $x$ & $x$ & $x$ & $x$ & $x$ & $x$ & \\
\hline Philippines & 1987 & $x$ & $x$ & $x$ & $x$ & $x$ & $x$ & & $x$ & $x$ & $x$ & $x$ & \\
\hline Indonesia & 1993 & $x$ & $x$ & & & $x$ & $x$ & & & $x$ & & $x$ & \\
\hline Vietnam & & $x$ & $x$ & & & $x$ & $x$ & $x$ & $x$ & $x$ & & & \\
\hline Lao PDR & & $x$ & $x$ & & & $x$ & $x$ & $x$ & $x$ & $x$ & & & \\
\hline Cambodia & & $x$ & $x$ & & & $x$ & $x$ & $x$ & $x$ & $x$ & & $x$ & $x$ \\
\hline Myanmar & & & & & & & $x$ & & & $x$ & & & \\
\hline \multicolumn{7}{|c|}{$\begin{array}{l}\text { NHRIs - National Human Rights Institutions } \\
\text { ICERD - Convention on The Elimination of all Forms of } \\
\text { Discrimination } \\
\text { ICCPR - International Covenant on Civil and Political Rights } \\
\text { ICCPR OP I - The Optional Protocol to the International } \\
\text { Covenant on Civil and Political Rights } \\
\text { ICCPR OP II - The Second Optional Protocol to the International } \\
\text { Covenant on Civil and Political Rights } \\
\text { ICESCR - International Covenant on Economic Social and } \\
\text { Cultural Rights } \\
\text { CRC - Convention of the Rights of the Child } \\
\text { CRC OP I - Optional Protocol to the Convention of the Rights of } \\
\text { the Child to the involvement of children in armed conflict }\end{array}$} & \multicolumn{7}{|c|}{$\begin{array}{l}\text { CRC OP II - Optional Protocol to the } \\
\text { Convention of the Rights of the Child on the } \\
\text { sale of children, child prostitution, and child } \\
\text { pornography } \\
\text { CEDAW - Convention on Elimination of all } \\
\text { Forms of Discrimination against Women } \\
\text { CEDAW OP I - Optional Protocol of the } \\
\text { Convention on Elimination of all Forms of } \\
\text { Discrimination against Women } \\
\text { CAT - Convention Against Torture } \\
\text { CAT OP - Optional Protocol of the } \\
\text { Convention Against Torture and Other Cruel, } \\
\text { Inhuman or Degrading Treatment or } \\
\text { Punishment }\end{array}$} \\
\hline
\end{tabular}

Sumber: http://globaljusticecenter.net/publications/Advocacytools.pdf, diakses pada 07 Agustus 2015.

terwujudnya tujuan dan sasaran. Deklarasi ini menyatakan bahwa piagam akan menegaskan kembali untuk peningkatan demokrasi, hak asasi manusia dan kewajiban, transparansi dan tata pemerintahan yang baik, dan penguatan demokrasi. Mereka juga menyatakan komitmen untuk mendirikan sebuah Eminent Persons Group (EPG) guna memberikan rekomendasi praktis dalam hal penyusunan piagam (Chongkittavorn, 2009).

Pada tahun 2006, Eminent Persons Group (EPG) akhirnya menyarankan pada ASEAN untuk menyertakan referensi pada pendirian mekanisme hak asasi manusia regional dalam Piagam ASEAN. Laporan Eminent Persons Group (EPG) ini didukung oleh para pemimpin ASEAN pada KTT ASEAN ke-12 di Cebu, Filipina pada Januari, 2007. Dukungan ini diwujudkan dalam Deklarasi Cebu melalui cetak biru Piagam ASEAN (ASEAN, 2006). Deklarasi Cebu dipimpin oleh sebuah High Level Task Force (HLTF) guna menyusun rancangan piagam untuk penandatanganan pada November 2007 selama KTT ASEAN ke-13 berlangsung di Singapura (CRI, 2007). High Level Task Force (HLTF) bertemu untuk pertama kalinya pada bulan Februari 2007 dan mulai menyusun piagam berdasarkan arahan dari ASEAN Summits ke-11 dan ke -12, Laporan Eminent Persons Group (EPG), dan dokumen penting ASEAN lainnya (CRI, 2007). 
Piagam ASEAN disetujui pada KTT ASEAN ke-13, November 2007 di Singapura dan ditandatangani oleh sepuluh negara anggota ASEAN. Piagam ASEAN inilah yang menjembatani pembentukan komisi hak asasi manusia ASEAN, Menteri Luar Negeri ASEAN membahas dan menyetujui dimasukkannya mekanisme hak asasi manusia regional. Mereka menunda keputusan dan akhirnya mendukung penyusunan Term of Reference (ToR) pada bulan Juli 2009 selama ASEAN Ministrial Meeting (AMM) ke-42 berlangsung di Phuket, Thailand. ASEAN Ministrial Meeting (AMM) ke-42 akhirnya mengadopsi Term of Reference (ToR) tentang pendirian ASEAN Intergovernmental Commission on Human Rights (AICHR) pada tanggal 20 Juli 2009 (Madina, 2009). ASEAN Ministrial Meeting (AMM) ke42 juga menyepakati bahwa, sebuah tim yang terdiri dari setiap negara anggota ASEAN yang pada awalnya merancang Term of Reference (ToR) akan juga merancang deklarasi sebagai komitmen politik para pemimpin ASEAN untuk meningkatkan perlindungan hak asasi manusia di kawasan Asia Tenggara (ASEAN, 2008).

Fakta di lapangan menunjukkan bahwa pelanggaran HAM masih terjadi pada batas yang luas dan dengan tingkatan yang beragam di negara-negara anggota ASEAN. Hal ini menunjukkan bahwa konsep-konsep hak asasi manusia di konstitusi nasional tidak berarti bahwa ketentuan hak asasi manusia akan benar-benar dihormati pada praktiknya. Di tingkat internasional tetap menjadi kenyataan bahwa hampir tidak ada satupun negara yang merupakan pihak dalam protokol opsional dalam perjanjian internasional hak asasi manusia inti. Jadi sebenarnya, tidak ada keluhan yang bisa dibawa ke badan hak asasi manusia PBB (RSIS, 2010).

Selain itu, beberapa negara telah membuat reservasi luas dalam perjanjian ini, hal ini menunjukkan kurangnya kemauan untuk sepenuhnya tunduk kepada norma-norma internasional hak asasi manusia.

Pemenuhan badan-badan ini dalam hal pelaporan juga sangat bervariasi dengan banyak negara yang terlambat menyampaikan laporan atau sama sekali tidak melaporkan. Fakta bahwa butuh waktu sekitar 15 tahun insentif untuk bertindak untuk membangun kerangka kerja hak asasi manusia regional juga menunjukkan bahwa secara umum, kemajuan hak asasi manusia di wilayah ini berjalan lambat.

\section{KESIMPULAN}

Pelembagaan HAM di ASEAN dalam bentuk AICHR mencerminkan meningkatnya partisipasi masyarakat dalam merespon berbagai persoalan HAM di Asia Tenggara. Walaupun berbagai persoalan muncul berkaitan dengan perumusan aturan main HAM di antara ke-10 negara ASEAN, AICHR juga menunjukkan bahwa ASEAN mulai memberikan perhatian pada persoalan-persoalan keamanan nontradisional. AICHR memang hanya berfokus pada reporting daripada investigating atau bahkan penegakan nilai-nilai HAM, namun demikian dinamika di antara negara-negara anggota ASEAN yang berujung pada pembentukan AICHR merupakan bagian penting dari pelembagaan regional di organisasi regional ini.

Walaupun AICHR sudah diratifikasi oleh negaranegara anggota ASEAN, pelaksanaannya masih terbatas pada isu-isu tertentu. Kesulitan pelaksanaan AICHR menjadi semakin komplek ketika praktek-praktek pelanggaran HAM terjadi di tingkat domestik. Prinsip non-interference sering dipakai sebagai upaya meningkatkan kedaulatan nasional sebuah negara, tanpa memperhatikan arti penting nilai-nilai kemanusiaan yang menjadi modalitas utama AICHR. Oleh karena itu, perluasan aspek-aspek yang dilindungi oleh AICHR dan pelaksanaannya di tingkat regional maupun nasional tetap menjadi tantangan mendasar bagi ASEAN.

\section{CATATAN AKHIR}

Kebebasan dalam survei dunia memberikan evaluasi tahunan negara tentang kebebasan global yang dialami oleh individu.Survei ini mengukur kebebasan dan kesempatan untuk bertindak secara spontan dalam berbagai bidang di luar kendali pemerintah dan pusat-pusat lain dari potensi dominasi menurut dua kategori besar yaitu hak-hak politik dan kebebasan sipil.Survei ini tidak menilai pemerintah atau kinerja pemerintah semata, melainkan dunia nyata hak dan kebebasan yang dinikmati oleh individu.

Setiap negara diberi peringkat numerik dari skala 1 sampai 7 untuk hak politik dan rating analog untuk kebebasan sipil. Peringkat 1 menunjukkan tingkat kebebasan tertinggi dan 7 adalah tingkat kebebasan terendah. Peringkat ini menentukan apakah suatu 
negara diklasifikasikan sebagai negara "bebas", "bebas sebagian", atau "tidak bebas" oleh survei.

\section{REFERENSI}

Agung Setiyo Wibowo, "Analisis Potensi dan Masalah AICHR dalam Upaya Pemajuan dan Perlindungan HAM", http://isjd.pdii.lipi.go.id/ admin/jurnal/7410250264_1412-0755.pdf, diakses pada 07 Agustus 2015. (n.d.).

ASEAN civil society groups unite for human rights body advocacy. (n.d.). Retrieved July 20, 2015, from http://www.hrwg.org/in/ siaran-pers/107-press-release-asean-civil-society-groups-unite-forhuman-rights-body-advocacy

ASEAN. (2006). Report of The Eminent Persons Group on The ASEAN Charter. Kuala Lumpur: ASEAN.

ASEAN. (2008, July 21). Terms of Reference For The High Level Panel on an ASEAN Human Rights Body. Retrieved August 10, 2015, from ASEAN: http://www.asean.org/storage/images/archive/HLPTOR.pdf

Askew, C. \&. (2004). Asia Pacific and Human Rights: A Global Political Economy Perspective. London: Ashgate Publishing Limited.

Caballero-Anthony, M. (1995). Human Rights, Economic Change and Political Development. In T. James T.H, Human Rights and International Relations in the Asia Pacific (pp. 47-48). London: Pinter.

Caballero-Anthony, M. (1995). Human Rights, Economic Change and Political Development. In J. T. Tang, Human Rights and International Relations in the Asia Pacific (pp. 47-48). London: Pinter.

Chongkittavorn, K. (2009, June 29). Activist Pressure Forcing AHRB into a Make or Break period. Retrieved Agustus 10, 2015, from The Nation Opinion: http://www.nationmultimedia.com/2009/06/ 29/opinion/opinion_30106257.php

CRI. (2007, Januari 14). KTT ASEAN Tandatangani Rangkaian Dokumen Deklarasi Cebu. Retrieved Agustus 10, 2015, from China Radio International: http://indonesian.cri.cn/ 1/2007/01/14/ 1@57116.htm

Eldridge, P. J. (2002). The Politics of Human Rights in Southeast Asia. London: Routledge.

Hashimoto, H. (2004). The prospects for a Regional Human Rights Mechanism in East Asia. New York: Routledge.

HRWGIndonesia. (n.d.). ASEAN civil society groups unite for human rights body advocacy. Retrieved July 20, 2015, from Human Rights Working Group: http://www.hrwg.org/in/siaran-pers/107-pressrelease-asean-civil-society-groups-unite-for-human-rights-bodyadvocacy

Jones, D. M. (2008). Security and Democracy: the ASEAN Charter and the dilemmas of Regionalism in Southeast Asia. International Affairs, 742.

Katsumata. (2009). ASEAN and Human Rights: Resisting Western Pressure or Emulating the West? The Pacific Review, 619-637.

Madina. (2009). AMM 42: ASEAN Semakin Siap Jelang Komunitas ASEAN 2015",. Retrieved Agustus 10, 2014, from http:// madina.co.id/v1/index.php/politik/6688-amm-42-asean-semakinsiap-jelang-komunitas-asean-2015.html

Madu, L. (2013). ASEAN 2011-2013: Bringing Non-State Actors Back In. The International Conference on International System on The End of The Westphalian Settlement: Contemporary Global
Challenges towards The Nation-State System. Yogyakarta: Universitas Muhammadiyah Yogyakarta.

Peerenboom, R. (2006). Human Rights in Asia: A comparative legal study of twelve Asian jurisdictions, France and the USA. New York: Routlegde.

Petcharamesree, S. (2009). The Human rights Body: A Test for Democracy Building in ASEAN. International IDEA, 11.

Phan, H. D. (2009). The ASEAN Intergovernmental Commission on Human Rights and Beyond. Asia Pacific Bulletin.

Piagam ASEAN Mulai Berlaku Desember. (n.d.). Retrieved Agustus 10, 2015, from "'", http://www.inilah.com/read/detail/62239/piagamasean-mulai-berlaku-desember

RSIS. (2010, June). Retrieved August 10, 2015, from http:// www.rsis.edu.sg/nts/HTML-Newsletter/alert/NTS-alert-jun1001.html

RSIS. (2010, June). Reserving the Rights not to Comply: ASEAN Legal Reservations to CRC and CEDAW. Retrieved August 10, 2015, from S. Rajaratnam School of International Studies: http:// www.rsis.edu.sg/nts/HTML-Newsletter/alert/NTS-alert-jun1001.html

Thio, L.-a. (2008). Implementing Human Rights in ASEAN Countries: Promises to Keep and Miles to Go Before I Sleep. In D. L. Shelton, Regional Protection of Human Rights (p. 1067). Oxford: Oxford University Press.

UNDP. (2015). The Human Development Index measures development by combining indicators of life expectancy, educational attainment and income into a composite human development index, the HDI. Retrieved Agustus 2, 2015, from http:// hdr.undp.org/en/humandev

UNHR. (2007). UN Universal Periodic Review. Retrieved Agustus 7, 2014, from Office of the High Commissioner on Human Rights: http://www.ohchr.org/EN/HRBodies/UPR/Pages/Documentation.aspx

Wahyuningrum, Y. (2009). ASEAN's Road Map Towards Creating a Human Rights Regime in Southeast Asia. Asian Forum for Human Rights and Development (FORUM-ASIA) (pp. 69-82). Bangkok: Human Rights Milestone: Challenges and Development in Asia.

Wibowo, A. S. (2010). Analisis Potensi dan Masalah AICHR dalam Upaya Pemajuan dan Perlindungan HAM. Jurnal Universitas Paramadina, 7 (Nomor 4).

WJP. (2015). "The World Justice Project Rule of Law Index 2010. Retrieved July 29, 2015, from World Justice Project: http:// www.worldjusticeproject.org/rule-of-law-index 